\title{
A EXPANSÃo DA CANA-DE-AÇÚCAR E A APTIDÃo AGRÍCOLA DAS TERRAS DA MICRORREGIÃO DO VALE DO RIO DOS BOIS - GO
}

\author{
Hellbia Samara M. de Carvalho RODRIGUES ${ }^{1}$ \\ Selma Simões de CASTRO²
}

\section{Resumo}

A mudança da matriz energética mundial, devido ao aquecimento global, estimulou no Brasil aumento da produção do bioetanol da cana-de-açúcar, menos poluente do que combustíveis fósseis. Em consequência houve uma rápida expansão do setor sucroalcooleiro desde o final do século passado, rumo ao Centro-Sul do Cerrado, principalmente ao Sul Goiano, onde domina o binômio carne x grãos. Nesta região, dentre as microrregiões produtoras de cana, encontra-se a Microrregião do Vale do Rio dos Bois (MRVRB), aonde a expansão foi menos vigorosa do que nas demais embora já tivesse sido beneficiada pelo programa federal Proálcool (1975 - 1979). Assim, objetivando compreender as causas dessa diferença, procedeu-se à análise da sua expansão canavieira e sua relação com a aptidão agrícola das terras. Elaboraram-se mapas de uso do solo, enfatizando as áreas de cana, e mapas de aptidão agrícola para 1985 e 2010, depois correlacionados entre si. Os resultados apontam a substituição das culturas de grãos alocadas nas áreas de maior aptidão agrícola, menos numerosas na MRVRB, e o deslocamento destas para áreas de pastagens e destas para áreas de remanescentes do Cerrado, reproduzindo o modelo frequente desse processo.

Palavras-chave: Aptidão agrícola. Análise espacial. Conflitos de uso do solo. Zoneamento Agroecológico da cana-de-açúcar.

\footnotetext{
1 Doutoranda do Instituto de Estudos Sócioambientais, Universidade Federal de Goiás. IESA UFG, Avenida Esperança, s/n, Campus Samambaia, Cep: 74690-900. Goiânia - Goiás - Brasil. E-mail: hellbiageografia1@gmail.com

2 Prof.a. Dra. do Instituto de Estudos Sócioambientais, Universidade Federal de Goiás. IESA - UFG, Avenida Esperança, s/n, Campus Samambaia, Cep: 74690-900. Goiânia - Goiás - Brasil. E-mail: selma.castro@uol.com.br
} 


\section{Abstract}

\section{Expansion of sugar cane and the suitability of agricultural land in the Microregion of Vale do Rio dos Bois - GO}

The change of the global energy matrix, due to global warming, stimulated in Brazil increased production of bioethanol from sugar cane, less polluting than fossil fuels. As a result, there was a rapid expansion of the sugarcane sector since the end of last century, toward the South Central region of the Cerrado, mainly in the South (2000), which dominates the binomial beef $x$ grains. In this region, among the micro-producers of sugarcane, is a microregion of Vale do Rio dos Bois (MRVRB), where the expansion was less powerful than the other although it had already been benefited by the federal program Proálcool (1975 - 1979). Thus, in order to understand the causes of this difference, we proceeded to the analysis of its sugarcane expansion and its relation with the agricultural suitability of the land. Drew up maps of land use, emphasizing the areas of sugar cane, and maps of agricultural suitability for 1985 and 2010, then correlated to each other. The results suggest that crop substitution of grains allocated in the areas of greatest agricultural suitability, less numerous in MRVRB, and the displacement of these to areas of pastures and those for areas of remnants of the Cerrado, reproducing the model frequently this process.

Key words: Aptitude agricultural. Spatial analysis. Conflict of soil use. Sugar cane agroecological zoning.

\section{INTRODUÇÃO}

O bioma Cerrado é um dos cinco biomas do Brasil, o segundo maior em área, originalmente equivalente a cerca de $23 \%$ do território nacional, superado apenas pela Floresta Amazônica (RIBEIRO e WALTER. 2008). Suas terras se tornaram alvo da expansão da fronteira agrícola na década de 1970, baseada na mudança da base técnica da agricultura, conhecida como modernização da agricultura, inspirada na Revolução Verde, a qual era ancorada no uso intensivo de insumos e maquinaria agrícola. Essa transformação favoreceu a mudança do paradigma do potencial de uso dos solos do Cerrado, até então considerados pobres e inadequados ao cultivo.

o modelo de desenvolvimento adotado foi o agroexportador, baseado na produção de commodities em grandes propriedades agrícolas monocultoras, que culminou no fortalecimento do binômio carne $x$ grãos, sobretudo soja e milho (CARRIJO, 2008; MIZIARA; FERREIRA, 2008; SILVA, 1996, 1999), na concentração fundiária e na criação de grandes complexos agroindustriais, economicamente estruturantes (KAGEYAMA et al., 1990).

Nesse mesmo período também ocorreu a primeira grande expansão canavieira do País motivada pela crise internacional de abastecimento de petróleo e incentivada pelo governo federal através do Programa do Álcool (Proálcool) de 1975 a 1979, visando à produção do álcool combustível automotor, que resultou no deslocamento e consolidação da liderança do setor para a região Sudeste do País, sobretudo o estado de São Paulo, agregado dos estados vizinhos, liderança essa que se mantém até os dias atuais.

No presente século XXI o Brasil vem passando por uma nova expansão sucroalcooleira, recentemente assumida como sucroenergética devido a cogeração de energia elétrica a partir do bagaço da cana. Essa expasnão foi motivada pela crise ambiental mundial relacionada ao aquecimento global, devido às emissões de GEE, 
resultantes, em grande parte, dos combustíveis fósseis derivados do petróleo, e da pressão para mudança da matriz energética para biocombustíveis, energia eólica e solar. O bioetanol, no caso, derivado da cana-de-açúcar, tornou-se a opção nacional e o Centro-Sul do Cerrado, o principal foco (CASTRO et al., 2010). Esse avanço da cana vem sendo considerado como um novo ciclo da expansão da Fronteira Agrícola (MIZIARA; FERREIRA, 2008) e considerada também como a Terceira Marcha para o Oeste (PIETRAFESA et al., 2012).

Como instrumento dessa política, o governo federal elaborou o Zoneamento Agroecológico da Cana, ZAECana (MANZATTO et al., 2009), que mapeou as terras com potencial agroecológico para a sua expansão e indica os tipos de uso pré-existentes, de modo a se tornar um regulador da expansão. O ZAECana estimou um total de 100 milhões de hectares aptos à cana no País, na maioria situados no Centro-sul do Cerrado, dos quais 12 Mha só no estado de Goiás. Assim, este se tornou alvo preferencial do processo de expansão canavieira, sobretudo sua região Sul e em particular a microrregião Sudoeste (SILVA, 1999 a,b; NASSAR et al, 2008; PIETRAFESA, et al., 2011).

Entretanto, a região do Sul Goiano foi indicada no ZAECana como de predomínio de média aptidão para o cultivo da cana, que, por outro lado já se encontrava geoeconomicamente consolidada, com base no binômio carne x grãos, sobretudo soja, e se tornara líder no agronegócio do Estado, desde meados do século passado. Todavia, influenciada, dentre outros fatores, pelo Plano Nacional de Agroenergia (PNA) (BRASIL, 2006) essa região passou por novas mudanças de uso do solo, desta feita substituindo áreas agrícolas e pastos pela cana (SPAROVEK, 2007; FISCHER et al., 2008; NASSAR et al., 2008, CASTRO et al., 2010; PIETRAFESA; SAUER, 2012). Estudos recentes realizados por Barbalho, Silva e Castro (2013), mapearam esse avanço da cana nessa região e confirmaram sua hegemonia no processo de expansão do setor.

No Sul Goiano, segundo vários autores, destacaram-se as microrregiões do Meia Ponte (ABDALA; CASTRO, 2010), de Quirinópolis (BORGES, 2012; BORGES; CASTRO, 2013) e do Vale do rio dos Bois (RODRIGUES, 2014). Nessas três microrregiões, a cana promoveu impactos tanto diretos como indiretos ao substituir áreas de soja, a qual se deslocou para áreas de pastagem e estas para áreas de remanescentes (CASTRO et al., 2010).

Ao contrário da microrregião de Quirinópolis, que não tinha cana até 2004 e desde então vem sendo considerada a nova centralidade da cana no Estado (BORGES, 2012), como na microrregião do Meia Ponte (ABDALA; CASTRO 2010), e na do Vale do rio dos Bois (RODRIGUES, 2014), os estudos indicam presença de cana desde o Proálcool, inclusive esta última foi um dos alvos preferenciais deste Programa, embora não tenha se destacado no cenário estadual, por causa ainda desconhecida. Todavia, estas duas agora revelam uma nova expansão, contudo com limitações também de origem desconhecida.

Este artigo tem como objetivo analisar a dinâmica espacial da expansão da cana-de-açúcar na microrregião do Vale do Rio dos Bois, de modo a compreender as suas relações com a aptidão agrícola e a identificar as possíveis causas da sua menor relevância no setor sucroalcooleiro estadual e nacional, embora apresente áreas aptas à sua expansão, segundo o ZAE Cana. 


\section{ÁREA DE ESTUDO}

A MRVRB está localizada a 16035'25"/1807'28"S e 5107'18"/5107'5"W, possui aproximadamente $13.653 \mathrm{Km}^{2}$ e integra a mesorregião Sul do estado de Goiás. Faz fronteira com a microrregião do Meia Ponte a Leste, a Oeste com a microrregião do Sudoeste de Goiás, à Nordeste com a microrregião de Goiânia, ao Norte com microrregião de Anicúns e à Noroeste com a de Iporá (Figura 1). Treze municípios e quatro usinas compõem a microrregião.
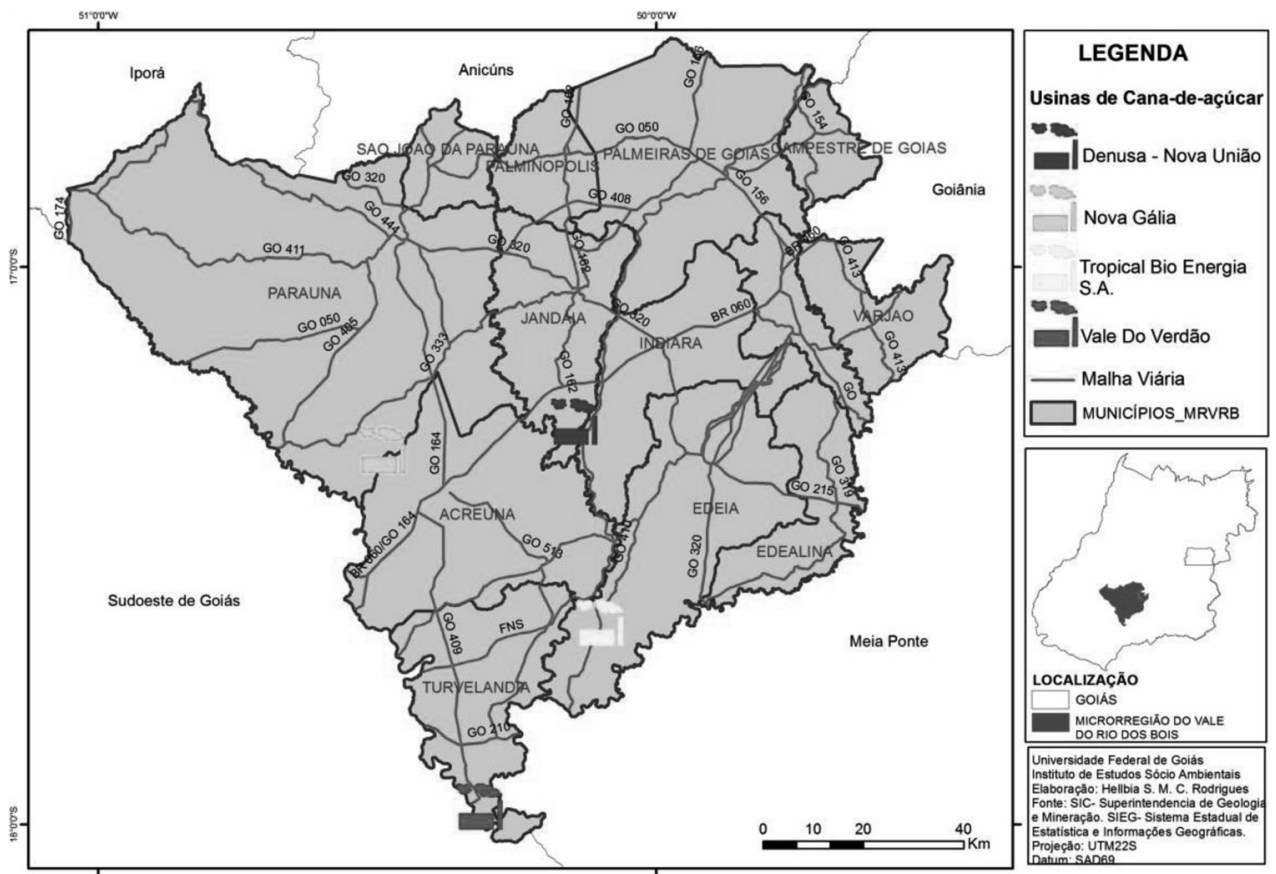

Figura 1 - Localização da microrregião do Vale do Rio dos Bois e das usinas em funcionamento

Constatou-se que as usinas da MRVRB estão localizadas em áreas servidas de ampla logística e condições edafoclimáticas favoráveis (ÚNICA, 2007) e que suas características físicas são favoráveis para o cultivo da cana-de-açúcar. A sudoeste e oeste da MRVRB, a principal litologia pertence à formação é Serra Geral (basaltos), que dá origem a relevos suaves e Latossolos Vermelhos argilosos de elevada aptidão para o cultivo da cana. Nas demais áreas a situação já não é tão favorável, como no norte e sudeste onde ocorrem os Ortognaisses e de oeste a noroeste onde há pequenas ocorrências de formações Anicuns e Itaberaí, da cobertura Detrítico-Laterítica, Jurubatuba e Supracustais que dão origem a relevos mais movimentados e a Argissolos e Cambissolos, dentre outros, menos aptos que os anteriores; e finalmente no noroeste ocorrem as formações Aquidauana, Vale do rio do Peixe e cobertura Detrítica Indiferenciada, também menos aptas.

Quanto ao relevo, ao norte e sudeste predomina a Superfície Regional de Aplainamento $\mathrm{V}$ (SRA V), no Noroeste há trechos das Superfícies Regionais de 
Aplainamento III e II (SRA II e III), ambas mais elevadas que a anterior, seguida de uma Zona de Erosão Recuante (ZER), uma faixa que as limita (LATRUBESSE; CARVALHO, 2006). As SRA são superfícies aplainadas, de topos amplos e declividade suave, associadas a solos espessos como os Latossolos, sendo favoráveis à mecanização agrícola. O clima é tropical subúmido, caracterizado pela sucessão de duas estações bem distintas, uma quente e úmida (outubro a março) e outra fria e seca (abril a setembro), alternância essa propícia ao cultivo de cana (BRAY, 1980).

Quanto aos solos, o Latossolo Vermelho distroférrico predomina a Nordeste, Oeste, Sul e Sudeste da região, compondo grande mancha contínua correlativa das SRA. Embora, seja solo de caráter álico e necessite de correção e adubação, é um solo favorável à agricultura intensiva em geral, inclusive cana (EMBRAPA, 2006). A noroeste ocorrem Neossolos Quartzarênicos (RQ) e pequenos setores com Argissolo Vermelho-Amarelo (PVA) e Gleissolo háplico (GX); ao Norte há manchas de Cambissolo háplico (CX) e Neossolo litólico (RL) (adaptado de NOVAES, 1983). Trata-se de solos em geral aptos à cana-de-açúcar (MAPA, 2007), porém em menor grau que os Latossolos Vermelhos.

Em síntese, pode-se afirmar que praticamente mais da metade da região é propícia ao cultivo da cana-de-açúcar e está servida por infraestrutura adequada à sua expansão.

\section{METODOLOGIA}

As principais ferramentas para o desenvolvimento da pesquisa foram o Sensoriamento Remoto e o Geoprocessamento. Assim, os mapas de uso e ocupação do solo e remanescentes do Cerrado foram confeccionados a partir de imagens do satélite Landsat TM5, disponibilizadas pelo Instituto Nacional de Pesquisas Espaciais (INPE), para os anos de 1985 e 2010, de órbita/ponto 222/72 e 223/72 do mês de Junho, por permitir uma boa identificação das áreas de cana, assim como o mapa disponibilizado pelo CANASAT do INPE (2009). As imagens foram trabalhadas na composição colorida tipo $\mathrm{R}(5), \mathrm{G}(4), \mathrm{B}(3)$. Após montado o banco de dados com as imagens, procedeu-se ao registro da imagem (georreferenciamento) com base em imagens Geocover, no Software ENVI. Todo o processo de confecção dos mapas foi executado no software SPRING. Inicialmente procedeu-se à segmentação, com o método de Crescimento de regiões, no qual se divide a imagem em regiões que devem corresponder às áreas de interesse da aplicação. Entende-se região como um conjunto de pixels contíguos, que se espalham bidirecionalmente e que apresentam uniformidade. Após esta etapa, procedeu-se à classificação da imagem em classes distintas de uso e cobertura, no mesmo software. Terminado o processo de classificação, os mapas foram exportados para o formato shapefile, onde passaram pela última etapa, já no software ArcGIS, de classificação visual propriamente dita, onde cada polígono gerado em cada mapa foi classificado conforme a respectiva imagem ao fundo. Para tanto, foi utilizada chave de classificação com base em Ribeiro e Walter (2008), conforme quadro 1.

Na classificação dos polígonos com cana-de-açúcar foi utilizada a mesma metodologia do CANASAT (INPE, 2009), que também utilizou imagens Landsat TM5 para o mapeamento, e com o método de classificação supervisionada e fotointerpretação talhão por talhão. 
Quadro 1 - Chave de interpretação adotada para classificação da imagem

\begin{tabular}{|c|c|c|c|c|c|}
\hline \multirow{2}{*}{$\begin{array}{l}\text { Classes de } \\
\text { Formações }\end{array}$} & \multirow[b]{2}{*}{ Classes de Uso } & \multicolumn{4}{|c|}{ Características } \\
\hline & & Textura & Tonalidade & Porte & $\begin{array}{c}\text { Aspectos } \\
\text { Associados }\end{array}$ \\
\hline \multirow{3}{*}{$\begin{array}{l}\text { Formação } \\
\text { Campestre }\end{array}$} & Campo Limpo & $\begin{array}{l}\text { Lisa, } \\
\text { homogênea }\end{array}$ & $\begin{array}{l}\text { Arroxeado/ } \\
\text { Preto }\end{array}$ & Baixo & Curso d'água \\
\hline & Campo Sujo & $\begin{array}{l}\text { Fina com } \\
\text { grânulos }\end{array}$ & $\begin{array}{c}\text { Verde } \\
\text { médio/rosa }\end{array}$ & Baixo & $\begin{array}{c}\text { Formas } \\
\text { irregulares, } \\
\text { Árvores } \\
\text { Irregulares. }\end{array}$ \\
\hline & Cerrado Ralo & Grossa & Verde Claro & Baixo & Árvores isoladas \\
\hline \multirow{2}{*}{$\begin{array}{l}\text { Formação } \\
\text { Savânica }\end{array}$} & Cerrado Denso & Homogêneo & Verde Médio & $\begin{array}{l}\text { Médio/ } \\
\text { Alto }\end{array}$ & Formas irregulares \\
\hline & Cerradão & Grossa & Verde Escuro & Alto & Formas irregulares \\
\hline $\begin{array}{c}\text { Formação } \\
\text { Florestal }\end{array}$ & Mata Ciliar & Homogêneo & Verde Médio & Alto & $\begin{array}{l}\text { Fundo de Vale; } \\
\text { Curso d'água }\end{array}$ \\
\hline- & Agricultura & $\begin{array}{c}\text { Fina/ } \\
\text { Aveludada/ } \\
\text { Granular } \\
\end{array}$ & $\begin{array}{c}\text { Rosa, Verde } \\
\text { Claro }\end{array}$ & $\begin{array}{c}\text { Rastei } \\
\text { ro }\end{array}$ & $\begin{array}{c}\text { Formas } \\
\text { Geométricas, } \\
\text { Pivôres } \\
\end{array}$ \\
\hline- & Pastagem & $\begin{array}{c}\text { Fina/ } \\
\text { Homogênea/ } \\
\text { Aveludada }\end{array}$ & $\begin{array}{c}\text { Clara com } \\
\text { algumas } \\
\text { variações }\end{array}$ & Baixo & $\begin{array}{c}\text { Geométricos/ } \\
\text { Trilhas/ Áreas } \\
\text { Isoladas/ Áreas } \\
\text { Rebaixadas e } \\
\text { Fundos de Vale } \\
\end{array}$ \\
\hline- & Área Urbana & Grossa & $\begin{array}{c}\text { Cinza } \\
\text { Claro/Médio }\end{array}$ & & $\begin{array}{c}\text { Formas } \\
\text { Geométricas/ } \\
\text { Arruamentos }\end{array}$ \\
\hline
\end{tabular}

Adaptado de Ribeiro e Walter (2008).

A elaboração do mapa de aptidão agrícola das terras seguiu as orientações do quadro guia para avaliação de Ramalho Filho e Beek (1995), cujo método de interpretação se apoia nas características físico-ambientais do solo, relevo, clima e vegetação. A elaboração necessita de variáveis físicas específicas e é gerada a partir do cruzamento dos mapas de textura, declividade, profundidade dos solos, drenagem e áreas inundáveis, e foi elaborado no software ArcGIS. Os parâmetros estabelecidos para a avaliação da aptidão agrícola das terras contemplaram: Níveis de manejo; Grupo de aptidão agrícola e Classes de aptidão agrícola, cuja definição está a seguir.

Níveis de manejo - O nível de manejo A é caracterizado por não haver aplicação de capital para manejo, melhoramento e conservação das condições das terras e das lavouras, mas não foi identificado na área. Assim, foram considerados os Níveis de manejo B e C para a área. O B é caracterizado pela aplicação de capital e de resultados de pesquisa para manejo, auxiliando no melhoramento e conservação das condições das terras. E o C é caracterizado uso intenso de capital e resultados de pesquisa para manejo, sendo que a motomecanização se encontra presente nas diversas fases da operação agrícola.

Grupos de aptidão agrícola - são três $(1,2,3)$ e correspondem à lavouras como tipo de uso das terras. Os grupos 4,5 e 6 correspondem à pastagem plantada, silvicultura e/ou pastagem natural e preservação da flora e fauna respectivamente. 
Classes de aptidão agrícola - são classificadas por análise comparativa dos graus de limitação atribuídos as terras, tipo de utilização e o nível de manejo. A simbologia correspondente está no quadro 2.

\section{Quadro 2 - Simbologia correspondente às classes de aptidão agrícola das terras}

\begin{tabular}{l|c|c|c|c|}
\hline \multirow{4}{*}{$\begin{array}{c}\text { Classe de aptidão } \\
\text { agrícola }\end{array}$} & Lavoura & $\begin{array}{c}\text { Pastagem } \\
\text { Plantada }\end{array}$ & Silvicultura & $\begin{array}{c}\text { Pastagem } \\
\text { Natural }\end{array}$ \\
\cline { 2 - 5 } & $\begin{array}{c}\text { Nível de manejo } \\
\text { A B C }\end{array}$ & Nível de manejo B & $\begin{array}{c}\text { Nível de manejo } \\
\text { B }\end{array}$ & $\begin{array}{c}\text { Nível de manejo } \\
\text { A }\end{array}$ \\
\hline Boa & A B C & P & S & N \\
\hline Regular & a b C & P & S & n \\
\hline Restrita & (a) (b) (c) & (p) & (s) & (n) \\
\hline Inapta & --- & - & - & - \\
\hline
\end{tabular}

Fonte: Ramalho e Beek (1995).

Convém lembrar que a classificação envolve certa subjetividade, mesmo diante dos atributos físicos levantados para a avaliação da aptidão agrícola da área. 0 quadro 3 apresenta as características interpretadas para a área de estudo, segundo os níveis de manejo, grupos e classes de aptidão agrícola.

\section{Quadro 3 - Simbologia da classificação da aptidão agrícola das terras*}

\begin{tabular}{|l|l|}
\hline Subgrupo & Caracterização \\
\hline $1 \mathrm{Bc}$ & $\begin{array}{l}\text { Terras com BOA aptidão para lavoura no nível de manejo C, REGULAR } \\
\text { no B e INAPTO no A }\end{array}$ \\
\hline $2(\mathrm{~b}) \mathrm{C}$ & $\begin{array}{l}\text { Terras com BOA aptidão para lavoura no nível de manejo C, RESTRITA } \\
\text { no (b) e Inapta no A }\end{array}$ \\
\hline $2 \mathrm{bc}$ & $\begin{array}{l}\text { Terras com REGULAR aptidão para lavoura no nível de manejo b e c e } \\
\text { INAPTA no A }\end{array}$ \\
\hline $4 \mathrm{P}-$ & Terras com BOA aptidão para pastagem plantada \\
\hline $4 \mathrm{p}$ & $\begin{array}{l}\text { Terras com REGULAR aptidão para } \\
\text { pastagem plantada }\end{array}$ \\
\hline $5 \mathrm{Sn}$ & $\begin{array}{l}\text { Terras com BOA aptidão para silvicultura e REGULAR para Pastagem } \\
\text { Natural }\end{array}$ \\
\hline $5 s(\mathrm{n})$ & $\begin{array}{l}\text { Terras com REGULAR aptidão para silvicltura e RESTRITA para } \\
\text { pastagem natural }\end{array}$ \\
\hline 6 & Terras INAPTAS ao uso \\
\hline
\end{tabular}

(*) Adaptado de Ramalho e Beek (1995). Org.: Rodrigues (2013); 
A análise comparada entre a aptidão agrícola elaborada com aquela apresentada no ZAECana (MANZATTO et al., 2009) e sua distribuição ao longo do período considerado, permitiu considerar três classes de aptidão agrícola (alta, média e baixa) discriminadas por tipo de uso atual predominante (Ag - Agropecuária, Ac - Agricultura e Ap - Pastagem). Os dados compilados foram recortados para a área de estudo utilizando o software ArcGIS.

\section{RESULTADOS E DISCUSSÃO}

O Centro-Sul do Cerrado, área preferencial para a expansão recente da monocultura da cana-de-açúcar, inclui o estado de Goiás, sobretudo sua mesorregião Sul onde a cana se destaca (BARBALHO et al, 2013). Tal expansão se deu em razão de seus atributos edafoclimáticos, como clima tropical com duas estações contrastadas e alternadas e solos de regular a elevada aptidão agrícola que somam 12 Mha (o Estado abrange pouco mais de $30 \mathrm{Mha}$ ), bem como de sua localização, do relevo suave de topos amplos, e da infraestrutura (energia, sistema viário) e logística presentes. Foi favorecida também pelas novas políticas federais para o setor, como o Plano Nacional de Agroenergia (MAPA, 2006) e o ZAECana (MANZATTO et al., 2009).

Resumidamente, o estado de Goiás já cultiva cana-de-açúcar desde o tempo colonial, mas contabilizou forte incremento na década de 1970 em consequência do Proálcool (1975-79), embora tenha ficado bem aquém daquele ocorrido em terras paulistanas, que detêm mais de $50 \%$ da produção nacional e do número de usinas do País. Acredita-se que isso foi devido, sobretudo, à logística e distância dos centros consumidores e de portos de exportação (CASTRO et al., 2010; CAMELINI; CASTILHO, 2011). Assim, até 2007 eram apenas 12 usinas em Goiás, dentre elas 2 situadas na MRVRB, de estudo, e atualmente são cerca de 40, sendo 4 na MRVRB.

O recente incremento do setor, desta vez mais forte que o anterior da década de 1970, promoveu a ampliação notável da área já cultivada, até 2010 (MAPA, 2012), bem como formou novas áreas de cultivo, antes ocupadas por grãos e pastos (NASSAR, 2008; CASTRO et al., 2010). Na mesorregião Sul Goiano (BARBALHO et al, 2016) vem se expandindo rumo ao Sudoeste Goiano, justamente onde se situa a MRVRB aonde as áreas antigas de cultivo foram simplesmente expandidas, embora consideradas como novas áreas, em que substituiu principalmente os grãos e secundariamente aos pastos, como ocorrido na microrregião do Meia Ponte (ABDALA; CASTRO, 2010) e de Quirinópolis (BORGES et al, 2010), sendo que nesta nem havia essa monocultura antes.

Considerando esses aspectos do processo, numa perspectiva de comparação, foram elaborados mapas de uso do solo e cobertura vegetal para dois anos, de 1985 e 2010, para a identificação das áreas de cana. O primeiro em função das consequências da expansão, da primeira grande expansão canavieira relacionada ao Proálcool (19751979) e o segundo considerado como a atual fase de expansão.

Analisando-se o mapa de uso do solo e remanescentes de 1985, pode-se notar que a MRVRB já apresentava intenso uso de suas terras, com cobertura vegetal natural já notavelmente fragmentada, cujas classes de fragmentos identificadas foram tanto da Formação Campestre, como da Savânica e da Florestal. Mas, a agricultura já se destacava como a principal classe de uso identificada nesse ano, abrangendo 40,33\% da sua área total, seguida pela classe de pastagem com 21,35\%. Nesse momento já se constatava pequena área de plantio de cana-de-açúcar, representando apenas $1,08 \%$ da sua área total e contava com 2 usinas (Figura 2). 


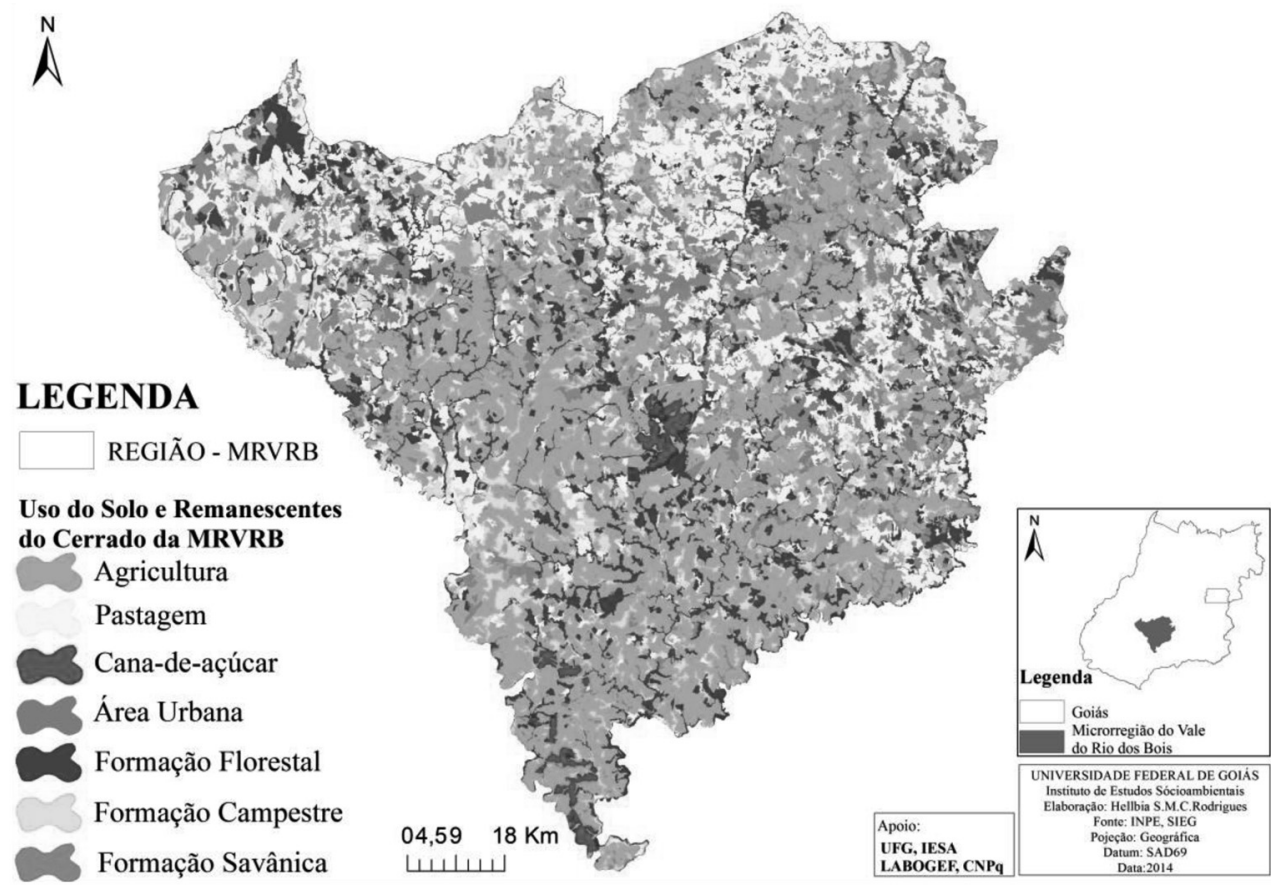

Figura 2 - Uso do Solo e Remanescentes do Cerrado da microrregião do Vale do Rio dos Bois, 1985

Ainda em 1985, quanto aos remanescentes de Cerrado, juntos eles cobriam $37 \%$ da área total, sendo que a Formação Campestre representava 9,38\% da área, a Formação Florestal 12,89 e a Formação Savânica 14,72\%. Os remanescentes concentravam-se nas áreas de relevo mais movimentado, associados a Cambissolos e Neossolos Litólicos. A fronteira agrícola já havia se consolidado e as áreas de declive plano a suave ondulado já se encontravam ocupadas por agricultura (MIZIARA et al., 2006).

Passados 25 anos, em 2010, o processo de transformação do uso e ocupação das terras da MRVRB prosseguiu, desta feita marcado pela recente expansão canavieira e já contando com 4 usinas em funcionamento. Nesse ano a agricultura representava cerca de $45 \%$ da área total, a pastagem $22 \%$ e a área específica de cultivo de canade-açúcar representava $5 \%$ da área total, ou seja, 5 vezes a anterior (1985), mas não correspondendo a um número expressivo na escala microrregional (Figura 3). Por outro lado, os dados da CONAB de 2008/2009, mostram que os municípios da MRVRB se destacam no Estado de Goiás quanto à produtividade da cana, como Acreúna com produtividade de $107.000 \mathrm{Kg} / \mathrm{ha}$, Paraúna com $104.630 \mathrm{Kg} / \mathrm{ha}$ e Edéia com 103.610 $\mathrm{Kg} / \mathrm{ha}$. Na produção, igualmente se destacam Acreúna com $178.000 \mathrm{mil} / \mathrm{t}$, Paraúna com $450.000 \mathrm{mil} / \mathrm{t}$ somadas a Turvelândia com $3.380 .000 \mathrm{mil} / \mathrm{t}$. O uso do solo apoiado em modernas tecnologias de cultivo da cana pode justificar essa produção. 


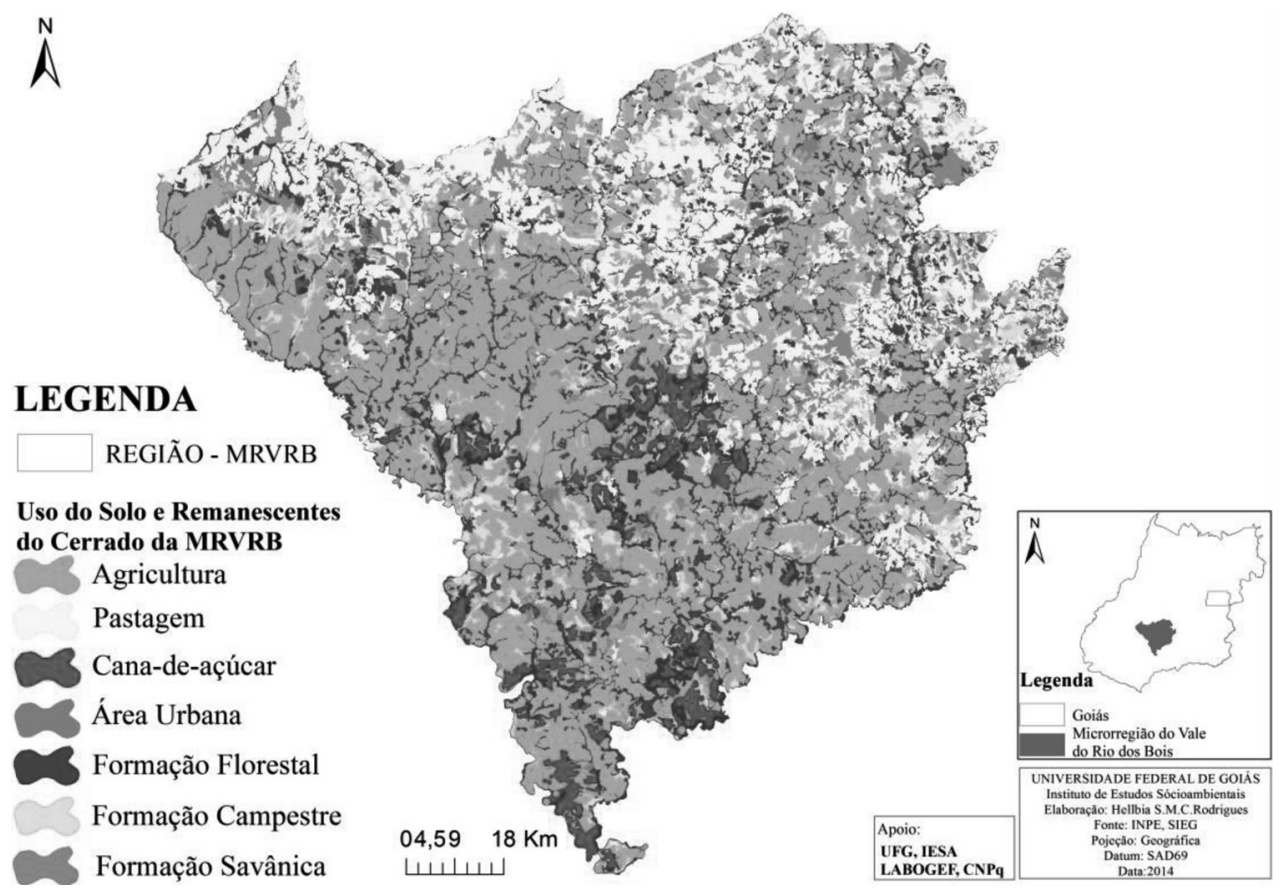

Figura 3 - Uso do Solo e Remanescentes do Cerrado da microrregião do Vale do Rio dos Bois 2010

Os remanescentes do Cerrado nesse ano de 2010 reduziram em quase $10 \%$ passando a $28 \%$ da área total da MRVRB. A Formação Florestal passou a 14,2\%, a Formação Campestre a 6,94\% e a Formação Savânica a apenas 6,52\%, o que permite afirmar que em relação a 1985, a fitofisionomia mais afetada foi a Formação Savânica que reduziu $8,2 \%$, seguida da Campestre que também reduziu 2,44\%, enquanto a Formação Florestal aumentou 1,31\%. Já a agricultura aumentou quase 5\%, entretanto a cana-de-açúcar aumentou $4,1 \%$, enquanto os pastos aumentam apenas $0,56 \%$ de área (Figura 4). Portanto, o crescimento da área de cana foi notável, embora não seja relevante para a MRBRB como um todo.

A figura 4 mostra também que a MRVRB conservou a mesma tendência agrícola de 1985 em 2010, apenas aumentando áreas de cultivo de grãos e ampliando bastante as de cana-de-açúcar, que juntas ultrapassaram mais de $60 \%$ da área total da MRVRB em 2010. Isto em detrimento das fitofisionomias Savânica e Campestre, sendo que manteve relativamente a mesma área de pastagem, correspondente a cerca de metade da área agrícola. Trata-se, portanto, de uma microrregião agrícola. Assim, convém ressaltar que a agricultura foi e ainda é a principal atividade da área na MRVRB. Mas, parece que as usinas de cana implantadas na região durante a vigência do Proálcool atuaram mais pontualmente, diferindo da dinâmica atual, haja vista o próprio crescimento das áreas cultivadas na região e a implantação de novas usinas, configurando uma nova dinâmica de fluxos na região. 


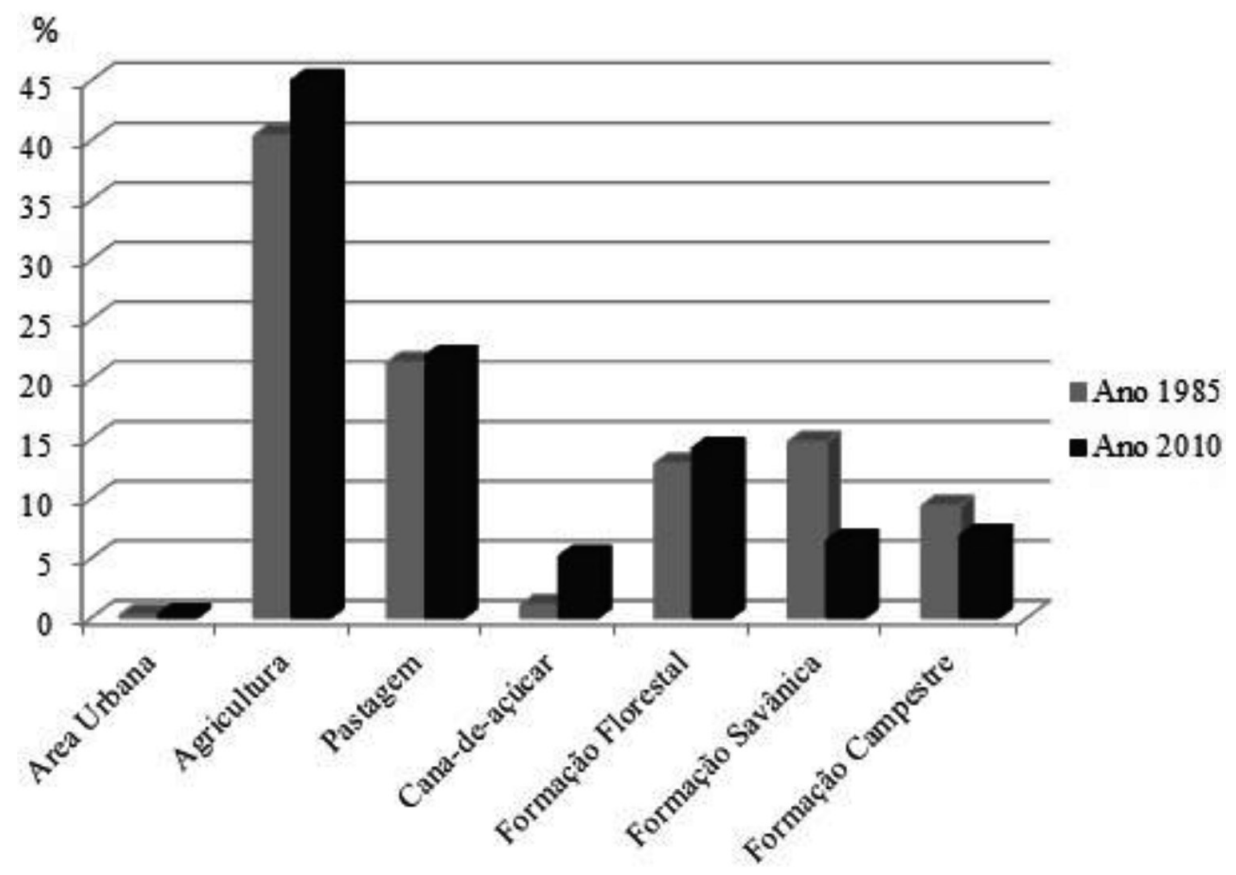

Figura 4 - Gráfico - Comparativo do uso das terras de 1985 e 2010 Fonte: Mapas das figuras 2 e 3.

A análise comparada dos mapas do uso das terras e remanescentes da MRVRB entre 1985 figura 2 e 2010 figura 3 permite ainda confirmar que a cana-de-açúcar substituiu a área de grãos existentes em 1985, sobretudo a soja, fato corroborado pelos dados do censo agrícola do IBGE (2010), reproduzindo a mesmo modelo das citadas microrregiões, ou seja, grãos » cana; pastos » grãos e remanescentes » pastos.

Ampliando-se a escala para a aptidão agrícola das terras já que a do ZAECana estava em 1:250.000, mas adotando-se a mesma metodologia (Ramalho e Beek, 1995) na escala $1: 100.000$, de modo a compará-lo com o de uso do solo e remanescentes com o intuito de identificar eventuais conflitos de uso, no que se refere principalmente às áreas de cultivo de cana. Assim, a figura 5 apresenta as classes de aptidão agrícola das terras identificadas para a MRVRB.

No mapa de aptidão agrícola da figura 5 o subgrupo de maior área é o 1 bC, correspondendo a metade $(50,44 \%)$ da área total da MRVRB, dominante no centrosul e norte da microrregião e que contempla as terras com boa aptidão para lavoura no nível de manejo C (intensivo), caracterizado pelo elevado investimento de capital e tecnologia de manejo e aplicando resultados de pesquisa. Vale lembrar que a motomecanização está presente nas diversas fases do sistema produtivo da cana e que essa classe se localiza em áreas de relevo variando de plano a suave ondulado e com predomínio dos Latossolos.

Trata-se, portanto, da melhor classe de aptidão para cultivo da cana. Ocorrendo de forma também expressiva segue-se o subgrupo $5 \mathrm{~s}(\mathrm{n})$, com $21,69 \%$ das terras, 
correspondentes às terras com aptidão agrícola regular para silvicultura e restrita para pastagem natural situadas em manchas rumo a leste. Nela são encontrados os Cambissolos e relevos mais movimentados. As áreas inaptas representam 7,86.

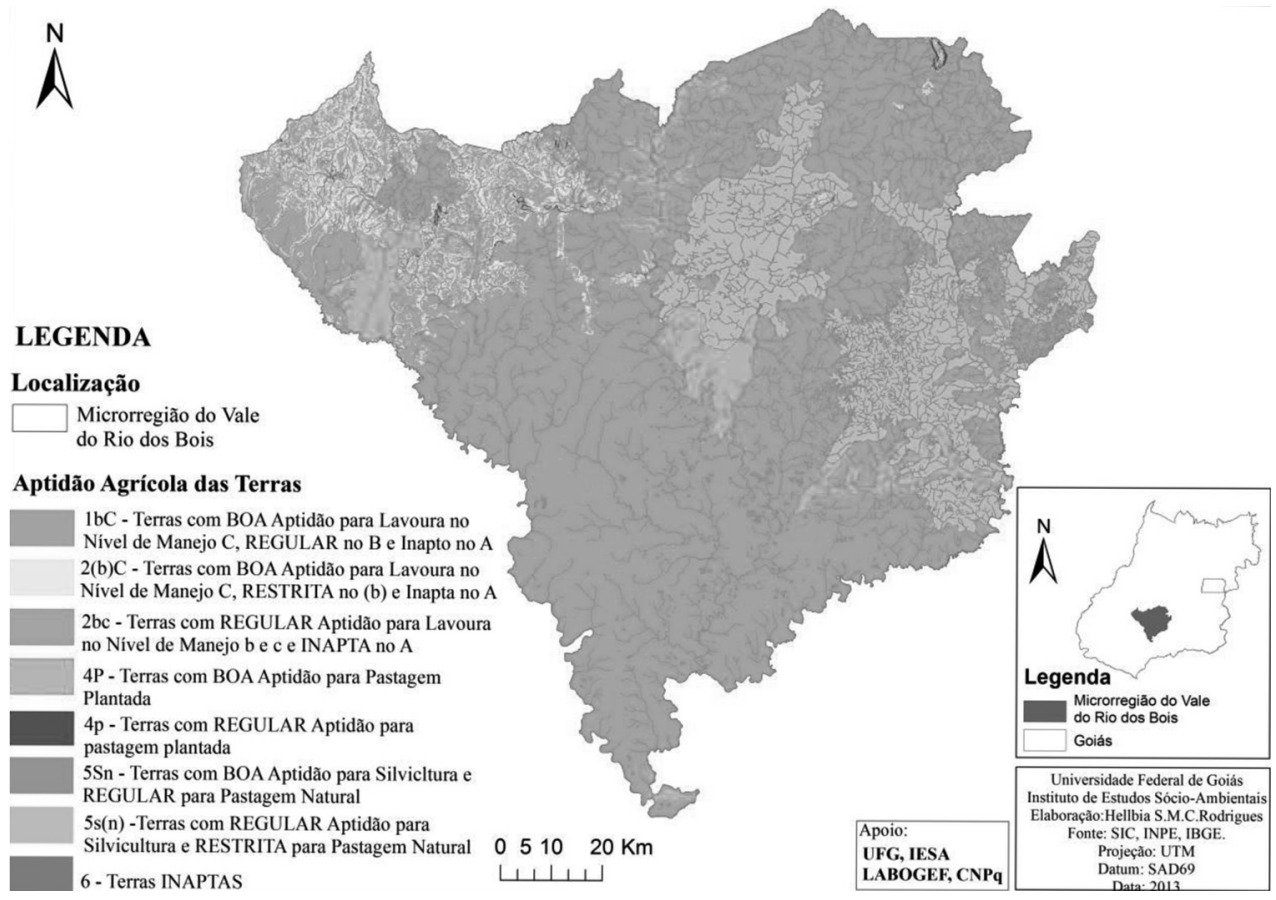

Figura 5 - Aptidão Agrícola da Microrregião do Vale do Rio dos Bois

Os demais subgrupos somam cerca de $15 \%$ e apresentam individualmente em manchas descontinuas e com áreas pouco expressivas, nos quais podem se destacar: o subgrupo 2 (b)C com $5,72 \%$ das terras em pequenas manchas dispersas ao norte e noroeste, com boa aptidão para lavoura no nível de manejo $C$, restrita no (b) e Inapta no $A$, seguida pela 2 bc, com $4,74 \%$ de terras com aptidão regular para lavoura no nível de manejo B e c e inapta no A a noroeste. Finalmente os subgrupos 4P que representam 5,85\% com boa aptidão agrícola para pastagem plantada, disposto em manchas ao centro, o $4 \mathrm{p} \operatorname{com~} 2,75 \%$ de aptidão regular para pastagem plantada e as terras do subgrupo $5 \mathrm{Sn}$ representam quase $1 \%$ da área total, com boa aptidão para silvicultura e regular para pastagem natural, ambos em pequenas manchas pontuais dispersas.

Comparando-se o mapa de aptidão agrícola figura 5 com o de uso e remanescentes figura 3 pode-se constatar que as áreas de cultivo de cana se situam em áreas aptas ao seu cultivo, e substituindo áreas agrícolas existentes em 1985 (Figura 2), ao contrário do que foi proposto no PNA-Plano Nacional de Agroenergia (MAPA, 2006), em que as áreas para a expansão deveriam ser preferencialmente as áreas de pastagem degradada. Por outro lado, não há conflitos de uso do ponto de vista da aptidão, mas de disputa de terras como assinalado por Abdala e Ribeiro (2010). 
O proposto pelo ZAECana citado figura 6 e os dados dela extraídos são apresentados na tabela 1 . Convém lembrar que a classe em branco corresponde às áreas que já possuíam cultivo de cana-de-açúcar do ano de 2006 e áreas inaptas ao plantio, com declividade superior a $12 \%$, além de áreas de preservação permanentes (FERRAZ, 2012).

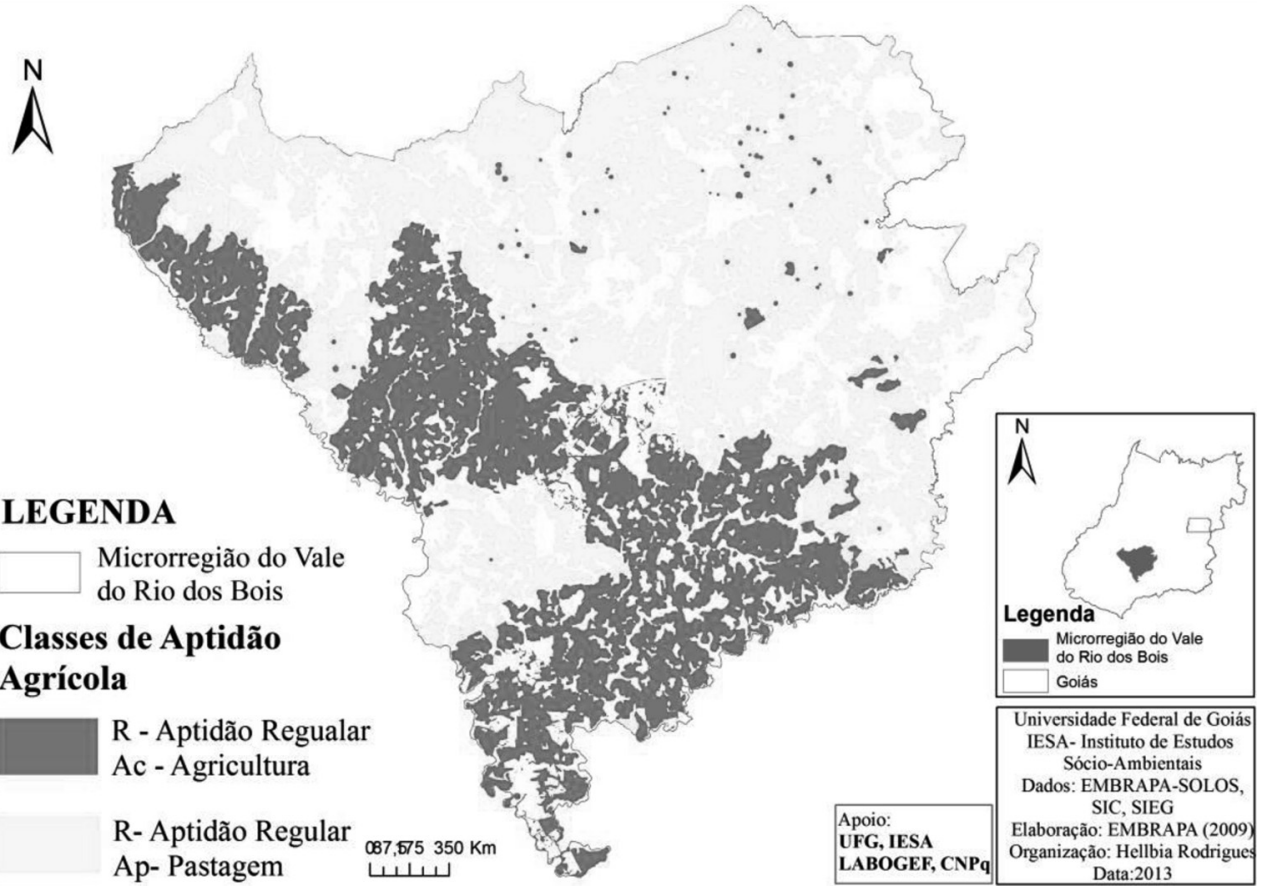

Figura 6 - ZAE- Aptidão Agrícola Para Cultivo de Cana

Fonte: ZAAECana (Manzatto et al., 2009). Organização: Rodrigues (2012).

\section{Tabela 1 - Áreas de Aptidão Agrícola para Cultivo de Cana segundo o ZAE}

\begin{tabular}{l|l|c|c}
\hline \multicolumn{1}{c|}{ Classe } & \multicolumn{1}{|c|}{ Descrição } & $\mathrm{Km}^{2}$ & $\%$ \\
\hline $\mathrm{R}-\quad$ Ap & $\begin{array}{l}\text { Áreas aptas ao cultivo com aptidão agrícola } \\
\text { MÉDIA, atualmente utilizadas com pastagens. }\end{array}$ & $5.282,92$ & 38,46 \\
\hline $\mathrm{R}-\quad$ Ac & $\begin{array}{l}\text { Áreas aptas ao cultivo com aptidão agrícola } \\
\text { MÉDIA, atualmente utilizadas com agricultura. }\end{array}$ & $3.667,77$ & 26,96 \\
\hline & $\begin{array}{l}\text { Áreas inaptas ao cultivo da cana-de-açúcar. E } \\
\text { áreas de cultivo de cana. }\end{array}$ & $4.641,31$ & 34,14 \\
\hline
\end{tabular}


Com base na figura 6, para a MRVRB são $8.950,69 \mathrm{Km}^{2}$ de áreas aptas ao plantio de cana, correspondendo à menos de $70 \%$ da sua área total, mas de qualquer forma maior do que a indicada anteriormente, e que reproduz a mesma trajetória da expansão da fronteira agrícola da década de 1970, isto é preferencialmente sobre solos e relevos mais aptos.

Por outro lado, dada a participação da cana na área total da MRVRB, convém chamar a atenção para o fato de que não é a principal produtora de cana-de-açúcar do estado de Goiás, pois que Borges et al. (2011) demonstram que a microrregião de Quirinópolis (MRQ) desempenha esse papel de nova centralidade do setor, como exposto Vale a pena lembrar que a MRQ, segundo Borges e Castro (2010), tem maior área apta para a expansão da cana-de-açúcar do que a MVRB. Portanto, nem os edafoclimáticos e nem a logística justificariam a questão da sua liderança no Estado, exceto a proximidade da hidrovia (canal de São Simão) e do Nó Modal que se conectará à Ferrovia Ferronorte (BORGES, 2010), portanto uma questão de logística (CAMELLINI \& CASTILHO, 2010) . O município de Quirinópolis já é o maior produtor de cana do Estado, tendo superado Santa Helena, que até 2010 era o município líder do ranking e que possui área plantada bem acima da MRVRB. Na MRQ a cana-de-açúcar em 2010 cobria 116.003ha da sua área total e contava com 7 usinas. Nesse mesmo ano a MRVRB possuía quase $70 \mathrm{mil}$ ha de sua área plantados com cana-de-açúcar, e apenas 4 usinas em funcionamento.

Além do fato da cana ocupar preferencialmente os Latossolos Vermelhos em relevos amplos e suaves ocupados com grãos nessas microrregiões, o que também poderia explicar esse quadro seria também o fato de contarem ambas, MRVRB e Santa Helena, com usinas antigas e talvez manejos superados, ao contrário da MRQ começa do começo, com usinas inteiramente novas e manejos mais atualizados, além de variedades mais adequadas. Mas isso precisa ser mais bem investigado. Em síntese, total de área apta e idade do sistema poderiam explicar o fato da MRVRB e nem Santa Helena não terem assumido/mantido a liderança no Estado. Isto se explicaria ainda e muito provavelmente pela logística e pela presença de usinas antigas que demandam muito capital para se modernizarem, manejos ultrapassados e variedades provavelmente pouco praticadas na nova expansão, o que necessita também ser mais bem investigado.

Fato interessante é que Silva e Castro (2010), ao analisarem o uso do das terras da MRQ de 2000 a 2010, constataram que a expansão iniciou-se a leste-nordeste sobre áreas de grãos e solos de maior aptidão agrícola (Latossolos Vermelhos) e que a expansão se projeta para oeste em terrenos de menor aptidão que estavam ocupados com pastagem e dominados por outros solos, como o Latossolos Vermelho Amarelo.

Assim, ao que parece, a aptidão desempenhou papel relevante no processo de expansão da cana na MRVRB, bem como o fato de substituírem os grãos que dominavam, reproduzindo o mesmo modelo que em outras microrregiões do estado de Goiás. Mas, a área disponível com solos de maior aptidão é menor na MRVRB do que na MRQ ou Santa Helena.

\section{CONSIDERAÇÕES FINAIS}

A aptidão agrícola do ZAECana aponta que menos de $70 \%$ da área da MRVRB são aptos ao cultivo de cana-de-açúcar e sua presença é cada vez maior na região, mas não ultrapassa cerca de $5 \%$ da sua área total, o que significa pouca relevância da cana até 2010. 
Nessas áreas não há conflito de uso quanto à aptidão agrícola. No entanto, dado ter ocorrido substituição de culturas (grãos) pela cana-de-açúcar, em particular soja, podem ocorrer disputas por terras.

Por outro lado, essa substituição foi vantajosa do ponto de vista do preparo do solo, devido o cultivo dos grãos tê-los manejado adequadamente, sobretudo para a soja alternada com milho ou sorgo ou milheto, estando os mesmos prontos para o novo uso com cana, sem necessidade de grandes investimentos no preparo e nem novos desmatamentos.

Essa dinâmica reproduz o observado em outras microrregiões do estado de Goiás, em particular para o Sul Goiano como um todo. Todavia, contraria o PNA, que indica como prioritárias de expansão para a cana-de-açúcar as pastagens degradadas.

Da análise comparada dos mapas de uso e de aptidão agrícola para a cana pode-se concluir que a MRVRB, em sua maioria, apresenta usos em acordo com sua aptidão agrícola, sem conflitos de uso, embora não se descarte os impactos diretos e indiretos relacionados, como a disputa por terras além do manejo da própria canade-açúcar.

A razão de não ter se destacado provavelmente se encontra na maior competitividade da MRQ próxima da MRVRB e a logística instalada ou em vais de instalação.

Seria interessante aprofundar os estudos sobretudo em campo para ouvir os proprietários ou seus representantes das usinas e das fazendas que cultivam a cana, para confirmar essa ideia.

\section{REFERÊNCIAS}

ABDALA, K. ; CASTRO, S.S. Dinâmica do uso do solo da expansão sucroalcooleira na Microrregião Meia Ponte, estado de Goiás, Brasil. In: SEMINÁRIO LATINO-AMERICANO DE GEOGRAFIA FÍSICA, 6. Anais. Disponível em: HTTP://www.uc.pt/fluc/cegot/ VISLAGF/actas/tema3/klaus. Acesso em 5 de agosto de 2016.

ABDALA, K.; RIBEIRO, F.L. Análise dos Impactos da Competição pelo Uso do Solo no Estado de Goiás Durante o Período 2000 a 2009 Provenientes da Expansão do Complexo Sucroalcooleiro. Rev.Bras. de Economia, Rio de Janeiro v. 65 n. 4 / p. 373-400, 2011.

BARBALHO, M.G.S.; SILVA, A.A.; CASTRO, S.S. A expansão da área de cultivo da cana-de-açúcar na região sul do estado de Goiás de 2001 a 2011. Revista Brasileira de Ciências Ambientais - n. 29, p. 98-110, Set.; 2013.

BORGES, V. M. S.; CASTRO, S. S. Dinâmica da Expansão da Cultura da Cana-deaçúcar na Microrregião de Quirinópolis, GO: Subsídios Para Avaliação da Competitividade com Culturas de Grãos e Pastos. In: SEMINÁRIO DE PÓS-GRADUAÇÃO DA UFG, 7. Goiânia, 2010.

BRAY, S.C. A cultura da cana-de-açúcar no vale do Paranapanema: um estudo de geografia agrária. 1980, 304 p. Tese (Doutorado). Universidade São Paulo. 1980.

CAMELINI, J. H; CASTILHO, R. Etanol e o uso corporativo. Revista Mercartor. Fortaleza, v. 11, n. 25, p.7-18, mai/ago 2012. Disponível em: <http:// www.mercator.ufc.br/index.php/mercator/article/viewArticle/722>. Acesso em: 24 ago. 2012. 
CANASAT - Mapeamento da cana via imagens de satélite de observação da Terra. INPE - Instituto Espacial de Pesquisas Espaciais. Disponível em: <http:// www.dsr.inpe.br/canasat/> Acesso em 2013.

CARRIJO, E. L. de O. A expansão da fronteira agrícola no estado de Goiás: setor sucroalcooleiro. 2008, Dissertação (Mestrado em Agronegócio) - Universidade Federal de Goiás. Escola de Agronomia e Engenharia de Alimentos, 2008.

CASTRO, S.S. de; ABDALA, K; SILVA, A. A; BORGES, V. A expansão da cana-deaçúcar no cerrado e no estado de Goiás: Elementos para uma análise espacial do processo. Boletim Goiano de Geografia. v.30, n.1, p. 171-191, 2010.

EMBRAPA - EMPRESA BRASILEIRA DE PESQUISA AGROPECUÁRIA. Ministério da Agricultura, Pecuária e Abastecimento - MAPA. Zoneamento agroecológico da cana-de-açúcar / organização Celso Vainer Manzatto... [et al.]. - Rio de Janeiro: Embrapa Solos, 2009. 55 p.: il. - (Documentos / Embrapa Solos, ISSN 1517-2627; $110)$.

EMBRAPA. Sistema Brasileiro de Classificação de solos. Rio de Janeiro: Embrapa Solos, 2006 e 2013.

FERRAZ, R. P. D. Sistema de Indicadores para a Avaliação do Potencial de Sustentabilidade Hídrica e Monitoramento da Cultura da Cana-de-açúcar, Contribuição metodológica para o planejamento da expansão da atividade canavieira. Tese (Doutorado em Meio Ambiente) - Programa de Pós-graduação em Meio Ambiente, Universidade Estadual do Rio de Janeiro, Rio de Janeiro, 2012.

FISCHER, G.; TEIXEIRA, E. T. H.; HIZSNYIK, E. T.; VELTHUIZEN, H. V. Land use dynamics and sugarcane production. In: ZUURBIER, P. and VOOREN, J.V. (Edit.) Sugarcane Ethanol: contributions to climate change mitigation and the environment. 1st. ed. Wageniguen Publs. Wageninguen: 2008, 29-6.

GOMES, H.; TEIXEIRA NETO, A. Geografia: Goiás/Tocantins. UFG, Centro Editorial e Gráfica.1993, 227p.

IBGE - Intituto Brasileiro de Geografia e Estatística. Bases de dados CENSO 2010. Disponível em http://www.sidra.ibge.gov.br/ acesso em 05 de jul. 2012.

KAGEYAMA, A. O novo padrão agrícola brasileiro: do complexo rural aos CAIs. In: DELGADO, G. C. (Org.). Agricultura e Políticas Públicas. Brasília/DF: IPEA, v. 1, 1990, p. 113-223.

LATRUBESSE, E. M; CARVALHO, T. M. Geomorfologia do Estado de Goiás e Distrito - Secretaria de Indústria e Comércio. Superintendência de Geologia e Mineração. Goiás, 2006.

MACEDO, I. de C. (Org.). Doze estudos sobre a agroindústria de cana-deaçúcar no Brasil e a sua sustentabilidade. São Paulo: Berlendis e Vertecchia: ÚNICA - União da Agroindústria Canavieira do estado de São Paulo, 2005.

MAPA - Ministério da Agricultura, Pecuária e Abastecimento. Balanço nacional de cana-de-açúcar e agroenergia. Secretaria de Produção e Agroenergia. MAPA/ SPAE, 2007 e 2010.

MIZIARA, F. Expansão de fronteiras e ocupação do espaço no Cerrado: o caso de Goiás. In: Guimarães, L. D. A, SILVA, M. A. D, ANACLETO, T. C. (Org.). Natureza Viva Cerrado: caracterização e conservação. Cap.VII.,1.ed. Goiânia: Editora UCG, 2006.

MIZIARA, F.; FERREIRA, N C. Expansão da fronteira agrícola e evolução da ocupação e uso do espaço no Estado de Goiás - subsídios à política ambiental. In: GUIMARÃES, L. F. (Org.) A encruzilhada socioambiental: biodiversidade, economia e sustentabilidade no cerrado. Goiânia: Editora da UFG, 2008. 
MINISTÉRIO PÚBLICO DO ESTADO DE GOIÁS (2012). Levantamento de Usinas. Núcleo de Apoio Técnico - NAT Setor Sucroalcooleiro Centro de Apoio Operacional do Meio Ambiente. 2012.

NASSAR, A. M.; RUDORFF, L. B. A.; AGUIAR, D. A.; BACCHI, M. R. P.; ADAMI, M. Prospects of the sugarcane expansion in Brazil: impacts on direct and indirect land use changes. In: ZUURBIER, P.; VOOREN, J.V. (Edit.). Sugarcane Ethanol: contributions to climate change mitigation and the environment. 1st. ed. Wageniguen Publs. Wageninguen: 63-94, 2008.

PIETRAFESA, J.P.; CASTRO, S.S.; TRINDADE,S.P. A crescente produção sucroalcooleira em áreas de cerrado e o Estado de Goiás: contribuições ao estudo sobre indicadores de sustentabilidade, In: História ambiental: fronteiras, recursos naturais e conservação da natureza / In: FRANCO, J. L. A.; SILVA, S. D.; DRUMMOND, J. A.; TAVARES, G. G. (Org.). História Ambiental - Rio de Janeiro : Garamond, 2012. p. 311- 332.

PIETRAFESA, J. P.; SAUER, S.; SANTOS, A. E. A. Políticas de recursos públicos na expansão dos agrocombustíveis em Goiás: ocupação de novos espaços em áreas de Cerrado. In: PIETRAFESA, J. P.; SILVA, S. D. (Org.) Transformações no Cerrado: progresso, consumo e natureza. 1. ed. Goiânia: PUC, 2011, p. 93-122.

PIETRAFESA, J. P.; SILVA, S. D. de (Org.). Transformações no Cerrado: progresso, consumo e natureza. Goiânia: Ed. Da PUC Goiás, 2011. p. 155-170.

RAMALHO FILHO, A.; BEEK, K. J. Sistema de avaliação da aptidão agrícola das terras. $3^{a}$ ed. Rio de Janeiro: EMBRAPA-CNPS, 1995.65p.

RIBEITO, J. F.; WALTER, B. M. T. As Principais Fitofisionomias do Bioma Cerrado. In: (Org.), SANO, S. M.; ALMEIDA, S. P. de.; RIBEIRO, J. F. R. Cerrado: Ecologia e Flora. Embrapa Cerrados. Brasília, DF: Embrapa Informações Tecnológicas, 2008.

RODRIGUES, H. S. M. C. Expansão da Cana-de-açúcar na Microrregião do Vale do Rio dos Bois - Goiás. Dissertação (Mestrado em Geografia) - Programa de Pósgraduação em Geografia. Universidade Federal de Goiás - Instituto de Estudos Sócioambientais, Goiânia-GO, 2014.

SCHNEIDER, P.; GIASSON, E.; KLAMT, E. SCHNEIDER, P.; GIASSON, E.; KLAMT, E. Classificação Agrícola das terras: um sistema alternativo. Guaíba: Agrolivros. 2007. 72p.

SILVA, J. G. da. A nova dinâmica da agricultura brasileira. Campinas, SP: Universidade Estadual de Campinas - Instituto de Economia, 1996.

SILVA, J. G. da. O novo rural brasileiro. 2. ed. Campinas/SP: Editora do Instituto de Economia da Unicamp, 1999b. v. 1. 147p.

SILVA, A. A.; CASTRO, S. S. Dinâmica de uso da terra e expansão da cana-de-açúcar entre os anos de 2004 a 2010, na microrregião de Quirinópolis, Goiás. In: Transformações no uso da terra e na estrutura de solos no Cerrado em áreas de expansão da cana. Ateliê Geográfico - Goiânia-GO, v. 9, n. 2, p.114-135, ago/2015.

SILVA, W. F. da; AGUIAR, D. A. de; RUDORFF. B. F. T; SUGAWARA, L. M;AULICINO, T. L. I. N. Análise da expansão da área cultivada com cana-de-açúcar na região Centro-Sul do Brasil: safras 2005/2006 a 2008/2009. Instituto Nacional de Pesquisas Espaciais - São José dos Campos São Paulo. 2009. 467p. 
